\title{
99m Tc-Octreotide Uptake in the Uterus and a Subserosal Myoma Mimicking Tumoral Masses
}

\author{
Elahe Pirayesh ${ }^{1}$, Mahasti Amoui $^{1}$, and Majid Assadi ${ }^{2}$ \\ ${ }^{1}$ Department of Nuclear Medicine, Shohada e Tajrish Medical Center, Shahid Beheshti University of Medical Sciences, Tehran, Iran; \\ and ${ }^{2}$ The Persian Gulf Nuclear Medicine Research Center, Bushehr University of Medical Sciences, Bushehr, Iran
}

The diagnostic usefulness of somatostatin receptor scintigraphy in the localization of tumors has been evaluated in several studies. Here, we present the case of a patient with a subserosal myoma diagnosed by ${ }^{99 m}$ Tc-labeled octreotide acetate scintigraphy. Oval and ring-shaped areas of hyperactivity in the pelvis were confirmed on MR imaging to be the uterus and a subserosal myoma. The presented case indicates that somatostatin receptors may be present in the uterus and in leiomyomas, especially in young women, and demonstrates that somatostatin may be a promising therapy for treatment of myoma. The case also demonstrates that subserosal myoma or dislocation of the uterus can result in a false-positive diagnosis, highlighting the importance of correlative imaging for accurate interpretation of the study.

Key Words: somatostatin receptor scintigraphy; neuroendocrine tumor; uterine myoma

J Nucl Med Technol 2014; 42:77-78

DOI: 10.2967/jnmt.113.131581

\section{$\mathbf{S}$} matostatin receptor scintigraphy is the functional technique used to assess neuroendocrine tumors (1). The diagnostic usefulness of somatostatin receptor scintigraphy in the localization of tumors has been evaluated in several studies (1). Uptake on somatostatin receptor scintigraphy has also been observed in various cell elements such as lymphocytes, fibroblasts, and endothelium (1). Here, we present the case of a patient with a subserosal myoma diagnosed on ${ }^{99} \mathrm{~m}$ Tc-labeled octreotide acetate scintigraphy.

\section{CASE REPORT}

A 30-y-old woman in whom neuroendocrine tumor was suspected was referred to our department for somatostatin receptor scintigraphy. Her past medical history was remarkable only for long-term cough. She had a large mass in the left lung and multiple lesions in the liver. A biopsy of the liver lesions

\footnotetext{
Received Aug. 25, 2013; revision accepted Oct. 21, 2013.

For correspondence or reprints contact: Majid Assadi, Persian Gulf Nuclear Medicine Research Center, Persian Gulf Biomedical Sciences Institute, Boostan 19 Alley, Sangi St., Bushehr 75147, Iran.

E-mail: assadipoya@yahoo.com

Published online Jan. 30, 2014.

COPYRIGHT (c) 2014 by the Society of Nuclear Medicine and Molecular Imaging, Inc.
}

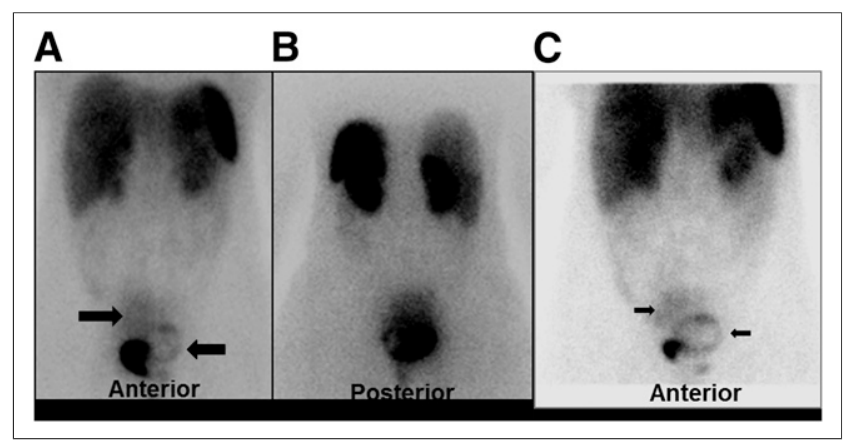

FIGURE 1. $99 \mathrm{~m}$ Tc-labeled octreotide acetate scintigraphy: whole-body planar view. (A and B) Images obtained 15 min after injection of $740 \mathrm{MBq}$ of $99 \mathrm{~m}$ Tc-labeled octreotide acetate show 2 areas of abnormal uptake in pelvis: oval region on right side (right arrow) and ring-shaped region on left side, compressing bladder (left arrow). Site of intense activity is bladder. (C) Image obtained $3 \mathrm{~h}$ after injection of $740 \mathrm{MBq}$ of $99 \mathrm{mTc}$-labeled octreotide acetate shows 2 areas of abnormal uptake in pelvis: oval region on right side (right arrow) and ring-shaped region on left side, compressing bladder (left arrow). Site of intense activity is bladder.

indicated metastatic low-grade neuroendocrine carcinoma. The immunohistochemistry results were positive for epithelial membrane antigen, cytokeratin, chromogranin, and Ki-67.

A scintigram was obtained at $15 \mathrm{~min}$ and $3 \mathrm{~h}$ after intravenous injection of $740 \mathrm{MBq}(20 \mathrm{mCi})$ of ${ }^{99 \mathrm{~m}} \mathrm{Tc}$-ethylenediammonium diacetate-tricine-hydrazinonicotinamideTyr0-octreotide. There were 2 areas of abnormal uptake in the pelvis, an oval region on the right side and a ringshaped region on the left side, compressing the bladder (Figs. 1 and 2). Sonography had also shown a pelvic mass. MR imaging correlation revealed a large, well-defined solid mass in continuity with the uterus, compatible with a large subserosal myoma (Fig. 3). Because of the lung mass, the patient received chemotherapy and octreotide treatment.

\section{DISCUSSION}

Uterine leiomyoma is the most common benign pelvic tumor in women $(2,3) .{ }^{111}$ In-octreotide uptake around an intramural myoma that shows peripheral calcification on CT has been attributed to inflammatory processes (2). However, in a preliminary study, somatostatin receptor 2 and 5 gene expression and increased expression during pregnancy 


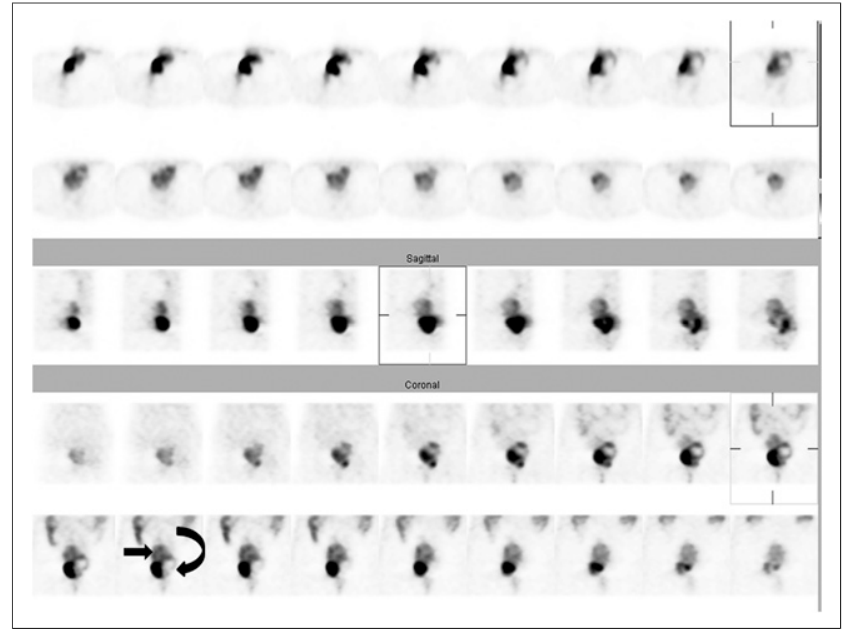

FIGURE 2. $99 \mathrm{mTc}$-labeled octreotide acetate scintigraphy: whole-body SPECT view. Study was performed $3 \mathrm{~h}$ after injection of $740 \mathrm{MBq}$ of $99 \mathrm{mTc}$-labeled octreotide acetate. Two areas of abnormal uptake are seen in pelvis: oval region on right side (straight arrow) and ring-shaped region on left side, compressing bladder (curved arrow). Site of intense activity is bladder. Top 2 rows are transverse images, middle rows are sagittal images, and bottom rows are coronal images.

were found in leiomyoma (3), and in a small clinical trial, administration of lanreotide (a long-acting somatostatin analog) resulted in reduction of uterine and myoma volumes (4).

Few studies of technetium-labeled octreotide compounds can be found in the literature. ${ }^{111} \mathrm{In}$-labeled octreotide scintigraphy, although a broadly used and helpful technique for the detection of somatostatin-expressing tumors, has several limitations such as high radiation burden, high cost, and limited availability. To overcome these shortcomings, octreotide compounds have been labeled with ${ }^{99 \mathrm{~m}} \mathrm{Tc}$. In one study, the diagnostic results of ${ }^{111} \mathrm{In}$-octreotide scintigraphy and ${ }^{99 \mathrm{~m} T c-h y d r a z i n o n i c o t i n a m i d e ~ D O T A T O C / ~}$ DOTATATE scintigraphy were found to be identical in 24 patients with different pathologic conditions (5).
FIGURE 3. MR imaging of abdominopelvic region. Large, well-defined solid mass is seen in continuity with uterus, compatible with large subserosal myoma (arrow).

\section{CONCLUSION}

Our case indicates that somatostatin receptors may be present in the uterus and in leiomyomas, especially in young women, and demonstrates that somatostatin may be a promising therapy for treatment of myoma. Subserosal myoma or dislocation of the uterus may result in a false-positive finding, highlighting the importance of correlative imaging for accurate interpretation of the study.

\section{REFERENCES}

1. Esfahani AF, Chavoshi M, Noorani MH, et al. Successful application of technetium-99m-labeled octreotide acetate scintigraphy in the detection of ectopic adrenocorticotropin-producing bronchial carcinoid lung tumor: a case report. J Med Case Rep. 2010;4:323.

2. Mena LM, Martin F, Jime'nez I, Ramos A. In-111 pentetreotide uptake in a uterine myoma. Clin Nucl Med. 2010;35:524-525.

3. Zandieh S, Schütz M, Bernt R, Zwerina J, Haller J. An incidentally found inflamed uterine myoma causing low abdominal pain, using Tc-99m-tektrotyd single photon emission computed tomography-CT hybrid imaging. Korean J Radiol. 2013; $14: 841-844$.

4. De Leo V, La Marca A, Vegni V, Raggi CC, Maggi M, Petraglia F. Quantitative determination of sst2 and sst5 gene expression in uterine leiomyomata and the effect of treatment with somatostatin analogue. Fertil Steril. 2003;80:1058-1059.

5. Kabasakal L, Sager S, Yilmaz S, et al. Comparison of In-111 octreotide scintigraphy with Tc-99m Hynic Toc/Tate scintigraphy in the same patient group for diagnosis of somatostatin receptor expressing tumors [abstract]. J Nucl Med. 2006;47(suppl 1):442. 